\title{
MANAGEMENT CONSULTING INTERVENTION CASE STUDY IN A COMPLEX AND TOXIC HOSPITAL ORGANIZATIONAL CULTURE
}

\author{
Dr. Darrell Norman BURRELL ${ }^{1 *}$
}

\begin{abstract}
Received: January 2020 | Accepted: March 2020 | Published: August 2020
Please cite this paper as: Burrell, D. N. (2020). Management consulting intervention case study in a complex and toxic hospital organizational culture, Holistica Journal of Business and Public Administration, vol. 11, iss. 2, pp. 100-114
\end{abstract}

\begin{abstract}
Healthcare organizations in turmoil often turn to management consultants to collect data, engage in analysis, evaluate processes, and make recommendations. This is a case study of an actual hospital with complex issues around organizational culture, organizational conflict, diversity, and talent management. The paper explores the intervention approaches used to address the toxic organizational cultural problems through the lens of organizational development, change management, and corporate behavioral theory.
\end{abstract}

Keywords: organizational development, management consulting, hospital administration, change management

\section{The object of research}

The focus of this research is the documentation of how healthcare management consultants identify deficiencies and areas of opportunity in business process improvement around talent and change management in a hospital setting. The aim of this case study and content analysis research to take an actual intervention and document approaches to provide a road map for management and organizational development consultants in healthcare and hospital organizations.

\section{Research method}

The paper uses content analysis from the academic literature theories to analyze, explain, and explore the complexities phenomenon in an actual hospital organization. This paper also uses case study applied action research to provide a road map for management and organizational development consultants in healthcare and hospital organizations.

\footnotetext{
${ }^{1}$ Florida Institute of Technology, Melbourne Florida, USA, dburrell2@thechicagoschool.edu

* Corresponding author
} 


\section{Introduction and Background}

Paez (2016) characterized the association between customer and consultant in four significant and influential roles: (1) The consultant that functions as a subject matter expert (2) the consultant that is reflective (3) the consultant that engages in critical analysis/evaluation, and (4) the consultant interpret and critiques dynamics, phenomenon, diagnoses symptoms, and prescribes solutions.

According to Paez (2016) and O'Cass and Ngo (2012), organizations create value not just by understanding the needs of their customers, but by deeply understanding the nature of their capabilities, competencies, and resources. Intellect capital and the ability to fully leverage that capital constructively and cohesively is one of the biggest challenges that organizations face (Paez, 2016). The inability to create an organizational culture that allows for the maximization of organizational talent can manifest itself in underperformance, employee disengagement, high turnover, toxic cultures, and employee turnover (Cheung-Judge \& Holbeche, 2015). Management consultants are used in organizational development interventions to help organizations better understand how they create value and fully leverage their intellectual capital and employee talent (Paez, 2016). Capabilities are classified into: (1) operational, e.g., repetitive processes at a functional level, and (2) dynamic, which are processes that allow the firm to change its resource base and look forward to meeting different strategic and competitive challenges however in real life there is not a clear cut frontier between both types (Paez, 2016).

Teece (2009) outlined that dynamic capabilities theory provides a framework to understand the value of management consultants in organizational development interventions is helps organizations understand and understand the existence of business processes, expertise, and competitive advantages that are critical to corporate growth, organizational longevity, and organizational sustainability.

Winterville Hospital brought a management consultant to address organizational challenges by the board and the new hospital CEO. The strategy would be to allow the management consultant to engage in a critical organizational development intervention as an outsider and make some recommendations in ways that might not have lasting results on the CEO. The name Winterville Hospital is a fictitious name for the actual hospital to protect the privacy and intellectual property of a real hospital. Winterville serves a large urban community in which 43 percent of residents are African-American, 17 percent are Latino American, 10 percent are Asian American, and $30 \%$ are Caucasian American. Currently, $90 \%$ of your doctors, physician assistants, and nurses in the hospital are Caucasian. There have been several local news stories and several pending lawsuits about complaints concerning instances of harassment, discrimination, and racism towards women and minority patients and employee staff. Currently, the nursing staff has a turnover rate of $40 \%$. The overall employee turnover rate for all positions is $33 \%$. There is a significant number of employee complaints and grievances against hospital management. Management complaints have gone up 300\% under the previous CEO. The 
HOLISTICA Vol 11, Issue 2, 2020, pp. 100-114

board has tasked management consultant to address the organization's cultural issues which becomes more complex as all US Hospitals respond to COVID 19.

Hospitals need the expertise and the collaboration of staff to respond in normal times but COVID 19 has made workplace culture a more critical aspect of the effective delivery of healthcare. Organizational challenges at Winterville also include severe shortages of testing supplies and long waits for test results (frequently 7 days or longer) have created complexities in tracking the health of patients and staff. The result is a more pressing need to fix and address talent management and workplace conflict issues in order to better care for patients seeking emergency care.

\section{Content and contexts from the literature}

The leading problems faced by all organizations include discrimination, a lack of diversity within the hiring process and amongst employees, a negative organizational culture, low employee job satisfaction, employee turnover issues, and destructive corporate management (Cheung-Judge \& Holbeche, 2015; Baragli \& Harnisch, 2008; Hogan \& Coote, 2014). It is critical for managers of an organization to possess the necessary skills that enable them to guide and direct organizational members through a diverse array of countless scenarios and challenges in a way that develops these members into better and more proficient employees. The goal of managers during organizational challenges should be to improve staff engagement, renew organizational loyalty, create a healthier and more positive mindset among employees, and to reduce staff refusal to accept adhere to changes or shifts within the company (Cheung-Judge \& Holbeche, 2015).

According to the book, The new managers tool kit: 21 things you need to know to hit the ground running by Don and Sheryl Grimme, it is critical for managers, especially newly appointed managers to execute their new roles and responsibilities successfully and to the best of their ability while also working to improve the overall productivity and functionality of their employees, themselves as leaders, and the organization as a whole (2009). Currently, Winterville Hospital is suffering from a lack of minority recruitment, recurring instances of harassment, discrimination, and racism towards minority patients and employee staff members, issues with employee turnover, and grievances against management within the hospital. If not properly handled and addressed, issues such as these can lead to the detriment of the hospital, which in turn can drastically affect the sizeable urban community in which it serves (Toussaint \& Adams, 2015; Daft, 2013; Schein \& Schein, 2016). By efficiently and adequately handling these issues, managers can improve workplace diversity, prevent instances of discrimination and racism, improve employee turnover rates, and create a more positive and beneficial management culture (Schein \& Schein, 2016; Josephsen, 2016).

\section{Improving Employee Culture and Job Satisfaction}

One of the leading issued faced by all types of organizations is change. Most employees meet organizational change with fierce resistance, and it is the sole responsibility of the 
managers to effectively handle this resistance and work to prevent it in the future (Holbeche, 2015). Change in an organization forces an alteration in culture, for either positive or negative. Change, regardless of the type, has a significant impact on employees and most considerably affects employee job satisfaction (Holbeche, 2015). Both organization development staff members and human resources employees can have an immeasurable influence on organizational culture and hob satisfaction (Cheung-Judge \& Holbeche, 2015). Organization development is defined as a "field of study regarding the advancement of the effectiveness of an organization through challenging processes such as change" (Cheung-Judge \& Holbeche, 2015, p. 15). The goal of this department is to improve organizational efficiency, team output and effectiveness, individual and group productivity, and employee skill and proficiency. The principal aim of human resources is "organizational improvement" (Cheung-Judge \& Holbeche, 2015, p. 23). This intervention approach ensures a solid foundation is set for the success of future employees, managers, and executives. These two departments have the unique authority to address and improve organizational culture and employee job satisfaction (Josephsen, 2016). Historically, when the organization has a positive culture established, employee job satisfaction shifts onto a positive trend in conjunction with creating an organizational culture with increased employee commitment. (Nelson \& Quick, 2013).

\section{Organizational Culture}

The culture of an organization is defined as a "pattern of basic assumptions that are considered valid and that are taught to new members as a way to think, perceive, and feel in the organization" (Nelson \& Quick, 2013, p. 592). Organizational leaders have the responsibility of designing, cultivating and facilitating the culture within an organization. These leaders establish important values deemed significant by the organization and outline guidelines regarding how employees should react to certain situations, behave in the workplace, and perform witchin the organization (Daft, 2013). The culture of an organization is further established through the behavior and reactions of managers, supervisors, and top executives (Nelson \& Quick, 2013). Organizational culture also sets rules on how members of all levels should interact, communicate, and form relationships, which has a direct impact on how employees treat one another. Managers determine which behaviors are considered acceptable and which practices are regarded as unacceptable (Daft, 2013). Positive organizations are less likely to encounter instances of harassment, discrimination, and racism within the workplace (Johnson \& Okoro, 2016). The culture of an organization is also set through rituals, symbols, ceremonies, norms, and artifacts (Nelson \& Quick, 2013). These characteristics of an organization play a critical role in forming, developing, shaping, and setting the foundation for an established organizational culture (Hogan \& Coote, 2014). The culture of an organization has a direct impact on the organization's potential for success, employee job satisfaction, member tolerance and acceptance of diversity within the workplace, and turnover rates (Nelson \& Quick, 2013). Since culture has a more considerable significant influence on employee behavior than traditional policies, procedures, authority of leadership, and decisions of executives, it is quintessential to facilitating, fostering, and ultimately achieving improved 
HOLISTICA Vol 11, Issue 2, 2020, pp. 100-114

employee performance, the creation of positive teams and teamwork, creativity, innovation, and overall organizational success (Hogan \& Coote, 2014).

According to Daft (2013), culture plays two crucial roles in an organization: enabling the successful organizational adaptation of the external environment and enabling the positive integration of members. As aforementioned, executive leaders establish corporate culture through their behaviors, actions, reactions, and daily interactions with other members of the workforce. This culture is further verified through the behaviors and actions of lower-level leaders, such as managers and supervisors (Nelson \& Quick, 2013). Internal integration is an essential piece of organizational culture as it enables employees to relate with one another and to form meaningful relationships (Nelson \& Quick, 2013). Internal integration facilitates the advancement of a mutually shared identity with the organization while also aiding the development of employee communication, cooperation, and coordination with one another (Daft, 2013). When internal integration is achieved and positively enacted, the organization can witness a positive shift in culture, employee job satisfaction, turnover rates, tolerance, and managerial leadership (Nelson \& Quick 2013, Daft, 2013).

\section{Clan Culture}

One of the most significant problems faced by Winterville Hospital is the lack of a positive organizational culture. The type of culture established at this hospital has created low employee job satisfaction, issues with employee turnover (specifically with nurses), instances of discrimination, harassment, and racism, and negative managerial leadership styles (Martinez, Beaulieu, Gibbons, Pronovost, \& Wang, 2015). It is evident that a shift in culture needs to occur to mend the issues faced by the hospital. The type of culture that would most benefit the Winterville Hospital is a clan culture (Tharp, 2015).

Certain cultures are more heavily focused on employees and employee job satisfaction than others. For instance, a mission culture focuses primarily on the ability and efficiency in which the members of an organization can accomplish the established organizational goals and purposes (Tharp, 2015). Clan culture is defined as the "involvement and participation of the organization's members and on rapidly changing expectations from the external environment" (Daft, 2013, p. 395). The focus of this culture is placed on the health and well-being of its members. Managers of clan cultures work diligently to ensure their staff members are taken care of, have their needs met, and possess high or improving levels of job satisfaction (Tharp, 2015). Members of this culture, in turn, feel valued and are more likely to place value on the beliefs and opinions of their peers (Tharp, 2015). An atmosphere of tolerance and respect is fostered through the cultivation of clan culture, which would significantly benefit Winterville Hospital (Martinez, Beaulieu, Gibbons, Pronovost, \& Wang, 2015). Therefore, by establishing clan culture in Winterville Hospital, members would see a positive shift in job satisfaction, turnover, attitudes, and tolerance (Martinez et al., 2015; Daft, 2013). 


\section{Implementing Culture Change}

Implementing a change in culture can be a challenging and monumental feat. Three different perspectives exist regarding the most effective way to achieve a shift in culture: the Pragmatic Approach, the Anthropological Approach, and the Pattern vs. Culture Change Approach (Cheung-Judge \& Holbeche, 2015). The Pragmatic Approach focuses first on the sought-after results and then determines which behaviors would best work to achieve the organizational goals. The Anthropological Approach perceives the change in culture from two commonly regarded beliefs about culture: (1) culture is what an organization possesses at a fundamental level and (2) the organization does not maintain a culture at all because the organization is in itself the culture (Cheung-Judge \& Holbeche, 2015). The Pattern vs. Culture Change Approach focuses on amending or entirely redefining the phrase "culture change" into a more straightforward idea. One prominent idea is "pattern shifting". Edgard Schein (2004), in Organization Development, defines culture as a "pattern of shared basic assumptions...that has worked well enough to be considered valid and, therefore to be taught to new members as the correct way to perceive, think, and feel in relation to problems" (as cited in Cheung-Judge \& Holbeche, 2015 , p. 195). It is significantly more comfortable for managers to recognize and distinguish patterns within an organization that it is for them to ascertain the established culture. Because of this, it is considerably easier to facilitate a change in patterns when attempting an overarching organizational culture shift (Cheung-Judge \& Holbeche, 2015). However, each organization is unique in its members and culture. As a result, management consulting and human resources staff members should work with managers within the Winterville Hospital to determine which approach would be the most efficient and most beneficial to implement a culture change (Cheung-Judge \& Holbeche, 2015).

\section{Changing Management Culture Through training, Engagement, and Coaching}

As aforementioned, organizational culture is a crucial element when addressing the issues faced by Winterville Hospital. This corporate culture hinges on the culture of management (Daft, 2013). A negative management culture can have detrimental impacts on the organization such as low morale, instances of harassment and verbally abusive behavior, problems of discrimination and racism, low job satisfaction, decreased productivity, low rates of retention amongst employees, and ultimately organizational failure (Hogan \& Coote, 2014). The most proficient way to change management culture is through training classes based on management styles and tactics, employee engagement, and leadership coaching (Daft, 2013; Schein \& Schein, 2016).

\section{Management Culture}

The culture of an organization is established through first through the management and is then reflected by the remainder of employees (Schein \& Schein, 2016). During the management training courses, facilitators should instruct students on the vital role leaders possess in the facilitation of employee learning and development. When challenges surface, managers must both facilitate and direct a behavioral change to successfully surmount the challenge (Schein \& Schein, 2016). Proficient leaders will be 
HOLISTICA Vol 11, Issue 2, 2020, pp. 100-114

able to successfully overcome challenges, which in turn will affect the type of culture shift that occurs (Daft, 2013). If the instructed change is successful and positive, organizational culture will trend positively as well, however, if the guided change is destructive, corporate culture will trend negatively, and the organization as a whole will suffer (Schein \& Schein, 2016). Therefore, Winterville Hospital should implement management training on leadership skill development, the importance of diversity, leadership coaching, change management, and healthy employee engagement (Schein \& Schein, 2016). This training should also include informative classes on the criticality of having a positive organizational culture and how it relates to management culture (Hogan \& Coote, 2014).

\section{Employee Engagement}

Employee engagement is a critical aspect of improving management culture and overall organizational success. Authors J. Lee Whittington, Simone Meskelis, Enoch Asare, and Sri Beldona (2017) stated that " $50 \%$ of workers in America are 'not engaged,' $17 \%$ of workers in America are 'actively disengaged,' and a mere one-third of workers in America are 'fully engaged'“ (p. 1). Employee engagement is directly correlated to workplace attitude, morale, employee behaviors, and interactions, the ability to cooperate, and operate as a team, therefore indicating that employee engagement has a significant impact on organizational culture (Whittington et al., 2017). The average cost of employee disengagement to the organization ranges anywhere from $\$ 450-\$ 550$ billion each year (Whittington et al., 2017).

Disengaged employees negatively affect the organization by performing unproductive tasks, missing workdays, and facilitating negative and counterproductive behaviors by coworkers (Whittington et al., 2017). Each of these actions not only costs the organization monetarily, but it put growth, reputation, productivity, and organizational health at risk (Whittington et al., 2017). To improve employee engagement, managers should work to create a meaningful environment and ensure their members feel valued (Bersin, 2015, as cited in Whittington et al., 2017). Managers can also improve employee engagement through goal setting and regular and constructive feedback sessions (Daft, 2013; Whittington et al., 2017). Goal setting enables employees to place value in their actions and allows them to evaluate their workplace performance and abilities (Daft, 2013; Whittington et al., 2017). Goal setting gives the employee authority and responsibility for their actions and capabilities, therefore subconsciously encouraging them to improve upon their skills to achieve the established goals (Whittington et al., 2017). Managerial behaviors play a significant role in how organizational culture is shaped (Daft. 2013). The best leadership style to create meaningfulness is transformational leadership (Daft. 2013). Transformational leadership "actively places value on the follower and constantly focuses on follower development," therefore fostering an environment of engagement (Daft, 2014, p. 271). The highest levels of employee engagement are achieved when employees perceive their organization as significant having purpose (Schein \& Schein, 2016). Managers at Winterville Hospital can facilitate this perception by actively representing the values and goals of the organization and consistently discussing the importance each 
organizational role has in achieving the hospital's overarching goals (Whittington et al., 2017).

\section{Leadership Coaching}

Leadership coaching is a term that refers to the "individualized process that builds a leader's capability to achieve short- and long-term organizational goals" ("What is Leadership Coaching?", n.d., p. 1). Leadership coaching is especially beneficial to the workplace environment and management culture because it is a highly personalized process that aims to suit the needs, goals, and desires of the individual ("What is Leadership Coaching?", n.d.). A study conducted in Australia regarding the impact leadership coaching has in a healthcare environment discovered that leadership coaching, when correctly done, could improve critical thinking, innovation, creativity, tolerance, insightfulness, and ability to achieve goals (Grant et al., 2017). The study also found that participants displaced lower levels of anxiety and stress after leadership coaching sessions (Grant et al., 2017). Lower levels of stress and anxiety can have beneficial impacts such as better quality relationships, healthier emotional states, increased productivity, and improved cooperation within the workplace (Grant et al., 2017; "What is Leadership Coaching?", n.d.). If implemented at Winterville Hospital, leadership coaching can have a variety of beneficial impacts on organizational culture, management culture, and overall workplace environment (Hogan \& Coote, 2014).

\section{Improving Employee Turnover}

Currently, Winterville Hospital is suffering from high rates of employee turnover. The nursing staff at this hospital has a turnover rate of $40 \%$, and the overall employee turnover rate for all hospital positions is $33 \%$. The term turnover rate is defined as the number or percentage of employees who leave an organization during a specific amount of time (Johnson \& Okoro, 2016). High turnover rates can significantly cost an organization as it forces managers to continually seek out new employees to replace the employees that left (Toussaint \& Adams, 2015). Employee turnover and employee dissatisfaction are expensive (Johnson \& Okoro, 2016). Turnover rates also increase stress levels for standard employees as it affects their work schedules, and it adds pressure on members of the group to teach the new employee and bring them up to speed on how the hospital operates (Toussaint \& Adams, 2015). High turnover rates, especially in hospitals also creates a safety concern for the patients as their provider who has extensive knowledge of their personal medical history has moved to another hospital (Johnson \& Okoro, 2016). This patient now has to inform the new staff member of their history and work to create a trusting relationship. However, that patient might choose to follow the provider to another hospital, therefore hurting the hospital's potential revenue and reputation with the public (Josephsen, 2016).

The first step in improving employee turnover rates at Winterville Hospital begins in the hiring process. Managers must actively seek out and hire people who will meet and exceed the established expectations and goals (Johnson \& Okoro, 2016). Employees who do not possess the skills, knowledge, or desire to perform proficiently in the organization 
HOLISTICA Vol 11, Issue 2, 2020, pp. 100-114

will only contribute to the detriment of the hospital and will more than likely resign, therefore increasing rates of turnover and cost to Winterville (Josephsen, 2016). It is also critical to have a welcoming and healthy organizational culture that makes employees feel welcomed, vested, and committed.

\section{Improving Minority Recruitment Processes}

Currently, healthcare organizations, such as Winterville Hospital suffer from a lack of minority doctors, nurses, and physician assistants across the board, but especially with the emergency room staff employment (Johnson \& Okoro, 2016). A study conducted by Greer Glazer, Barbara Tobias, and Tammy Mentzel (2018), discovered that Hispanic and African American minority groups represent $30.9 \%$ of the population in America; however, both of these minority groups represent a mere $8.5 \%$ of physicians and only $9 \%$ of registered nurses. Winterville Hospital serves a large urban community in which $43 \%$ of residents are African American, $17 \%$ are Latino American, $10 \%$ are Asian American, and $30 \%$ are Caucasian American. However, $90 \%$ of doctors, physician assistants, and nurses at Winterville Hospital are Caucasian, therefore displaying a severe lack of representation and indicating instances of discrimination within the hiring process. These low numbers are due to instances of discrimination in the hiring process and a lack of workplace diversity comprehensiveness (Glazer, Tobias, \& Mentzel, 2018).

\section{Discrimination in the Hiring Process}

Discrimination in the hiring process is defined as a "situation in which one or more minority groups are less likely to acquire a paid job or acquire a paid position under unfavorable conditions" (Zschirnt \& Ruedin, 2016, p. 1). The United States National Research Council defines discrimination as "differential treatment based on race that disadvantages a racial group and treatment based on inadequately justified factors other than race that disadvantages a racial group" (Zschirnt \& Ruedin, 2016, p.1). These two definitions underline the fact that discrimination is not always overt and is often subconscious. However, no matter the reasoning, discrimination in the hiring process can have detrimental impacts on the organization and the surrounding community as they are losing job opportunities and potential incomes as well (Glazer, Tobias, \& Mentzel, 2018). As aforementioned, discrimination is often an unconscious act. A common, yet subtle phenomenon that can lead to subconscious discriminatory decisions is called a heuristic. It is critical for managers to both understand and be aware of heuristics and how they can affect the organization (Zschirnt \& Ruedin, 2016). Heuristics are defined as "mental shortcuts the human brain utilizes to make decisions as quickly as possible (Josephsen, 2016 , p. 11). One common heuristic displayed in the hiring process is the "availability heuristic". This type of heuristic causes people to judge or perceive certain situations based on previous circumstances in similar contexts in which they can recall the quickest. Toxic and non-inclusive cultures are unhealthy for employees (Josephsen, 2016). Another common issue that can negatively affect the hiring process is a phenomenon titled "confirmation bias." Confirmation bias is defined as a "person's inclination to process information by identifying, construing, and deciphering information that is consistent with 
the person's preexisting beliefs" (Zschirnt \& Ruedin, 2016, p. 32). Confirmation biases create inhibitions in the ability of the hiring staff member's ability to perceive, interpret, judge, and approach a situation devoid of bias. When bias as a part of the hiring process, unlawful discrimination is likely to occur, which, as aforementioned, can have detrimental consequences to the organization (Zschirnt \& Ruedin, 2016).

\section{Strategies for Minority Recruitment}

To combat discrimination in the hiring process, Winterville Hospital should implement requirements for hiring managers to complete discrimination classes. These classes would instruct students on the various forms of discrimination can take, the implications of unfairness in the workplace, the consequences of discrimination concerning organizational proficiency and success, how to identify discrimination, and how to prevent bias (Johnson \& Okoro, 2016). One strategy to improve the recruitment of minorities is for Winterville Hospital to engage in community involvement and community outreach programs. The hospital could host a health fair which would not only provide medical services to local members in need, but it would also promote their hospital, its staff, and their dedication to help the local community (Glazer, Tobias, \& Mentzel, 2018). Winterville Hospital hiring managers should also play an active role in local medical schools to seek out minorities interested in the medical field while also allowing the students to interact with and make vital connections with their local hospital (Glazer, Tobias, \& Mentzel, 2018). Winterville Hospital should also ensure that hiring managers are representative of diverse minority groups. Constructive interventions would reduce instances of discrimination and racism while also putting minority candidates at ease, allowing for a smoother and more effective process (Johnson \& Okoro, 2016).

\section{Cultural Competency, Diversity, and Inclusion Training}

One of the most detrimental impacts an organization can experience is a lack of diversity, cultural competency, and inclusion (Glazer, Tobias, \& Mentzel, 2018). In recent months, there have been multiple incidences of local news outlets reporting about harassment, discrimination, and racism occurring towards minority patients and staff at Winterville Hospital. There have also been several pending lawsuits regarding these issues as well. These can have severe consequences for the future of Winterville Hospital if they have not experienced some impacts already. It only takes one incident of discrimination, harassment, or racism that goes unpunished or unrecognized to establish a negative atmosphere within the workplace (Glazer, Tobias, \& Mentzel, 2018). If these incidents are not correctly handled, they can quickly spiral out of control and evolve into common occurrences, generating a toxic and destructive environment in the workplace (Baragli \& Harnisch, 2008).

Corrosive workplace environments often negatively affect productivity, efficiency, organizational effectiveness, employee behavior and attitude, turnover rates, and corporate culture, which, as aforementioned, have significant impacts on organizational success. (Grimme \& Grimme, 2009). To prevent intolerance, discrimination, racism, and harassment from becoming a common occurrence at Winterville Hospital, managers 
HOLISTICA Vol 11, Issue 2, 2020, pp. 100-114

should create and implement diversity training for all employees. This training should discuss the importance of tolerance and diversity in the workplace and how to create an inclusive workplace environment (Schouler-Ocak et al., 2015). Upon the conclusion of this training, instances of harassment, racism, and discrimination at Winterville Hospital should trend downward, therefore creating a safer and more favorable environment for staff and patients alike (Schouler-Ocak et al., 2015).

\section{Diversity Training and Cultural Competency}

Diversity is defined at the "condition of being comprised of people with various backgrounds, cultures, beliefs, values, morals, and different other elements (Baragli \& Harnisch, 2008, p. 3). Diversity can have a multitude of advantages both within and outside of the workplace, such as the facilitation of progress, creativity, efficiency, innovation, interpersonal skills, and organizational development (Daft, 2013). Management consulting recommendations include hiring and actively adding employees who come from various backgrounds, religions, cultures, and races. These employees bring new perspectives, ways of thinking, and a more comprehensive knowledge base to the organization (Hubbard, 2008). Winterville Hospital would significantly benefit from creating and implementing diversity training. This training should mainly focus on how a diverse workforce brings a competitive edge to the organization and how culturally diverse employees enhance problem-solving skills, productivity, and organizational efficiency (Schouler-Ocak et al., 2015). Upon conclusion of the training, managers at Winterville Hospital should have a better understanding of diversity, inclusion, how to create a diverse workforce, how to interact with and be respectful of people stemming from different backgrounds, and how to encourage tolerance and inclusion from staff members (Grimme \& Grimme, 2009). These training sessions should include classroom instruction, online modules, guest speakers, and community involvement to maintain student attention and ensure learning is accomplished. Students learn best when they are involved and immersed in the curriculum (Mechanic at al., 2017).

Cultural Competency is defined as the "process by which individuals and systems respond respectively and effectively to people of all cultures, languages, classes, races and other diverse backgrounds in a manner that recognizes, affirms, and values the worth of individuals, families, and communities" (Baragli \& Harnisch, 2008, p. 10). A cultural competency training program should focus on how to respect one another's individual differences and how to protect and uphold each culture and religion present in the workplace (Schouler-Ocak et al., 2015). Facilitators of this training should discuss the importance of ensuring the individual differences displayed by employees does not negatively affect the workplace environment, but rather are "bridgeable" differences that can be used to learn more about one another and enhance employee interactions (Schouler-Ocak et al., 2015, p. 432). When conducted properly, cultural competency and inclusion training should improve employee self-awareness and knowledge of other cultures. The purpose of this training should be to ensure that employees and managerial staff are insightfully amending the way they view and think about various cultures (Mechanic et al. 2017). 


\section{Improving Organizational Efficiency by Cutting Operational Costs and Expenses}

The loss of organizational revenue, when experienced over a significant and continuous amount of time, can lead to the failure of the organization entirely. To begin trending upwards in revenue and efficiency, leaders must work to cut operational costs and expenses through a series of interventions (Sullivan, 2019). A few things leaders at Winterville Hospital can do to reduce operational costs and expenses are to embrace new technologies, outsource where applicable, invest in telehealth and telecommunication, critically examine inefficient areas and processes, cancel and or eradicate unproductive services, products, and procedures, and make the workplace welcoming (Sullivan, 2019).

Finally, when all cultural concerns are visibly improving, it is time to focus on ways to cut operational costs and expenses. Management consultants can often function as Lean transformation consultants that focus on business process improvement and improve productivity. Lean is a complete cultural transformation (Toussaint \& Adams, 2015, p.3). Laying the foundation involves all the necessary prework to be accomplished before starting a Lean transformation, to include collecting baseline data, selecting team members, and identifying the project scope. Culture does not shift without buy-in from the top-down (Toussaint \& Adams, 2015, p.21). The characteristics of management consulting are process experts, a total system focus, theory-based change management interventions (Cheung-Judge \& Holbeche, 2016, p. 10-11).

\section{Telehealth}

Winterville Hospital should seriously consider including telemedicine in their provided services. Telemedicine is a relatively new and rapidly advancing field in the medical community comprised of a range of services and capabilities ranging from emailing pictures of potential skin conditions to a dermatologist to utilizing Telestroke technology to assist someone experiencing a stroke (Lyuboslavsky, 2015). Telehealth refers to the broad range of health services and disciplines provided through the use of technologies associated with telemedicine. In contrast, telemedicine refers to the "exchange of medical information through electronic communication" (Lyuboslavsky, 2015, p. 7). Telehealth can be a cost-efficient service with the ability to reach a wide range of people that, before this technology, had no access to care. Telemedicine has the potential to connect patients with physicians hundreds of miles apart while providing real-time medical solutions (Lyuboslavsky, 2015).

\section{Other Ways to Cut Operational Costs}

Managers at Winterville Hospital can also cut operational costs and expenses by outsourcing, eradicating unproductive services, products, and members, and turning the organization into an environmentally friendly workplace. When applicable, outsourcing can save an organization time and money (Sullivan, 2019). Winterville Hospital could outsource people to advertise their hospital and to examine their processes, identify weak areas, and weed out inefficiencies. Approaches might include laying off unnecessary and unproductive employees, which is an unpleasant task but can save the hospital tens of 
HOLISTICA Vol 11, Issue 2, 2020, pp. 100-114

thousands of dollars yearly (Sullivan, 2019). Another way to cut expenses is to make the office space as green as possible. Installing fluorescent lighting, improving insulation, and cutting back on physical waste can reduce energy use, heating and cooling costs, and utility costs (Sullivan, 2019).

\section{Conclusions and final management consulting recommendations}

In total, Winterville Hospital is facing a multitude of devastating issues negatively affecting the organization and its employees. These issues include a negative organizational culture, low employee job satisfaction, a negative management culture, high employee turnover rates, a lack of minority recruitment, a deficiency of cultural competency, diversity, and inclusion within the workplace, and unnecessary operational costs and expenses. To combat these issues, Winterville Hospital should implement a clan culture, which would facilitate a priority to take care of employees, which would subsequently boost morale, develop interpersonal relationships, and improve job satisfaction (Martinez, Beaulieu, Gibbons, Pronovost, \& Wang, 2015; Daft, 2013). Winterville Hospital should also introduce management training that focuses on employee engagement and leadership coaching, which would positively change the current management culture (Daft, 2013; Schein \& Schein, 2016). To decrease employee turnover rates, leaders at Winterville Hospital should create clear and attainable employee expectations and take a critical look at their hiring process to ensure those who are hired possess the same values, beliefs, and ideals modeled by the organization (Josephsen, 2016). To improve minority recruitment and to decrease discrimination in the hiring process, managers should engage in community involvement opportunities such as health fairs and student outreach programs (Glazer, Tobias, \& Mentzel, 2018; Johnson \& Okoro, 2016).

Winterville Hospital is also experiencing issues relating to harassment, racism, and discrimination directs towards patients and employees. To combat this, the hospital should implement and facilitate diversity, cultural competency, and inclusion training (Grimme \& Grimme, 2009; Mechanic et al., 2017). Finally, Winterville Hospital has decreased in revenue over the past few years and needs to cut operational costs and expenses. To accomplish this, leaders should invest in telehealth technologies and services, outsource when applicable, eradicate unproductive services, products, and members, and turn the hospital into an environmentally friendly organization (Lyuboslavsky, 2015; Sullivan, 2019). By accomplishing the recommendations mentioned above, Winterville Hospital should experience considerable improvements in culture, tolerance, job satisfaction, turnover rates, revenue, and overall organizational success (Cheung-Judge \& Holbeche, 2015; Grimme \& Grimme, 2009; Josephsen, 2016).

\section{References}


HOLISTICA Vol 11, Issue 2, 2020, pp. 100-114

Baragli, M, \& Harnisch, L. (2008). Cultural Competency Diversity at DHS: Valuing, Embracing, and Implementing [PDF file]. Retrieved http://www.dhs.state.or.us/tools/diversity/tools/cctools-managers.pdf

Cheung-Judge, M.-Y., \& Holbeche, L. (2015). Organization Development: A practitioner's guide for OD and HR (2nd ed.). Philadelphia, PA: Kogan Page Limited.

Daft, R. L. (2013). Organization theory and design. $12^{\text {th }}$ ed. Cincinnati, OH: South-Western College Publishing.

Glazer, G., Tobias, B., \& Mentzel, T. (2018). Increasing healthcare workforce diversity: Urban universities as catalysts for change. Journal of Professional Nursing, 34(4), 239-244. doi:10.1016/j.profnurs.2017.11.009

Grant, A. M., Studholme, I., Verma, R., Kirkwood, L., Paton, B., \& O'Connor, S. (2017). The impact of leadership coaching in an Australian healthcare setting. Journal of Health Organization and Management, 31(2), 237-252. doi:10.1108/JHOM-09-2016-0187

Grimme, D., \& Grimme, S. (2009). The new managers tool kit: 21 things you need to know to hit the ground running. New York, NY: AMACOM

Hogan, J., Coote, L. (2014). Organizational culture, innovation, and performance: A test of Schein's model. The Journal of Business Research, 67(2), 1609-1621. doi: 10.1016/j.jbusres.2013.09.007

Hubbard, E. E. (2008). The diversity discipline: Implementing diversity work with a strategy, structure, and ROI measurement focus. Petaluma, CA: Global Insights Pub.

Johnson, A., \& Okoro, M. (2016). How to recruit and retain underrepresented minorities: From kindergarten through fulltime positions, what works to engage aspiring minority researchers in studying ocean science? American Scientist, 104(2), 76.

Josephsen, G. (2016). Hiring high quality emergency medicine physician assistants and nurse practitioners: Finding the right people and retaining talent. Medicus.

Lyuboslavsky, V. (2015). Telemedicine and telehealth 2.0: A practical guide for medical providers and patients. United States: Victor Lyuboslavsky.

Mechanic, O. J., Dubosh, N. M., Rosen, C. L., \& Landry, A. M. (2017). Cultural competency training in emergency medicine. Elsevier. doi:10.1016/j.jemermed.2017.04.019

Nelson, D.L., Quick, J.C. (2013). Organizational behavior: Science, the real world, and you (8 ${ }^{\text {th }}$ e.d.). Mason, $\mathrm{OH}$ : South-Western Cengage Learning.

O'Cass, A. \& Ngo, L. V. (2012). Creating superior customer value for B2B firms through supplier firm capabilities. Industrial Marketing Management, 41 (1): 125-135.

Paez, E. A. (2016). Creation of value in management consulting: A resources and dynamic capabilities perspective (Order No. 10121517). Available from ProQuest Dissertations \& Theses Global. (1794933756).

Redding, D. (2018). What Does the Nike Logo Mean? Retrieved from https://www.culturecreature.com/nike-logo-meaning/.

Schouler-Ocak, M., Graef-Calliess, I. T., Tarricone, I., \& Qureshi, A. (2015). EPA guidance on cultural competence training. Elsevier. doi:10.1016/j.eurpsy.2015.01.012

Teece, D. J. (2009). Dynamic Capabilities \& Strategic Management, New York, N.Y., Oxford University Press.

Tharp, B. M. (2015). Four Organizational Culture Types [PDF file]. Retrieved from https://pdfs.semanticscholar.org/b0e2/fd342fcf402920e264f15070276b79be1e25.pdf

Toussaint, J., \& Adams, E. (2015). Management on the mend: The healthcare executive guide to system transformation. $1^{\text {st }}$ ed. Appleton, WI: ThedaCare Center for Healthcare Value. 
HOLISTICA Vol 11, Issue 2, 2020, pp. 100-114

Schein, E. H., \& Schein, P. (2016). Organizational culture and leadership. Retrieved from https://ebookcentral.proquest.com

Sullivan, M. (2019). Operating Costs: Understanding and reducing them for your business. Retrieved from https://quickbooks.intuit.com/r/expenses/8-ways-reduce-operatingcosts/.

What is Leadership Coaching? (n.d.). Retrieved September 29, 2019, from http://www.nextlevelleadershipcoaching.com/what-is-leadership-coaching/.

Whittington, J. L., Asare, E., Beldona, S., \& Meskelis, S. (2017). Enhancing employee engagement: An evidence-based approach. Cham, Switzerland: Palgrave Macmillan. doi:10.1007/9783-319-54732-9

Zschirnt, E., \& Ruedin, D. (2016). Ethnic discrimination in hiring decisions: a meta-analysis of correspondence tests 1990-2015. Journal of Ethnic \& Migration Studies, 42(7), 1115-1134. https://doi-org.portal.lib.fit.edu/10.1080/1369183X.2015.1133279 